\title{
Fluorescent naphthalene-based benzene tripod for selective recognition of fluoride in physiological condition
}

\author{
BARUN KUMAR DATTA, CHIRANTAN KAR and GOPAL DAS* \\ Department of Chemistry, Indian Institute of Technology Guwahati, Guwahati 781 039, India \\ e-mail: gdas@iitg.ernet.in
}

MS received 29 November 2013; accepted 21 July 2014

\begin{abstract}
Aluminium complex of a naphthalene-based benzene tripod ligand system has been reported for the selective recognition of fluoride in aqueous medium in physiological condition. The ligand can selectively recognize $\mathrm{Al}^{3+}$ through enhancement in the fluorescence intensity and this in situ formed aluminium complex recognizes fluoride through quenching of fluorescence. The receptor system detects fluoride in nanomolar range. The sensing property was extended for practical utility to sense fluoride in tap water, pond water and river water.
\end{abstract}

Keywords. Chemosensor; fluoride anion; fluorescence; environmental.

\section{Introduction}

Development of selective optical signalling systems for anions has received considerable attention in recent decades due to their important roles in biological and environmental processes. ${ }^{1}$ Fluoride, important for its health effect on humans and nowadays elicited by mounting evidence, its severe toxicity makes it a controversial subject. While in Anglo-Saxon countries such as USA, UK and Australia, water fluoridation, i.e., the addition of fluoride into public water supplies, is a wellestablished practice since $1945 ;^{2}$ there is a growing concern about fluoride contamination, only in part anthropogenic, over large areas of Asia, Africa and South America. ${ }^{3}$ Therefore, while fluoride has a gentle effect up to $1 \mathrm{ppm}$ concentration, it seems to be toxic at higher doses. ${ }^{4 a}$ Over the years, high concentration of the fluoride anion in the environment and in drinking water has been related to the occurrence of several types of pathological conditions in humans such as osteoporosis, neurological and metabolic dysfunctions, and more recently cancer. ${ }^{4}$ Some studies have also reported the effects of fluoride on the biochemistry of organisms. It seems that DNA synthesis and the activity of some enzymes, as well as the metabolism of nutrients, can be severely influenced by the presence of fluoride. ${ }^{5}$ A recent study reveals that many bacteria possess RNA structures (riboswitches) which selectively respond to fluoride by triggering the expression of specific genes. These, in

*For correspondence turn, encode a series of fluoride binding or transporting proteins which can reduce the concentration of fluoride, if that is too high. ${ }^{6}$ Fluoride is also important in industrial applications and transformations, especially in steel making and aluminium refining, and it is a well-established reagent in organic synthesis. ${ }^{7}$ Novel applications of fluoride have been discovered in the fields of ion batteries, ${ }^{8}$ for enhancing the photo current in supramolecular solar cells ${ }^{8 \mathrm{~b}}$ and in 18F-PET imaging $;{ }^{8 c, d}$ and, in the future, it might play a role in the construction of superconducting ${ }^{8 \mathrm{e}}$ and hydrogen storage materials. ${ }^{8 \mathrm{e}}$ Intense fluoride contamination in the surroundings of industrial areas has been often detected. As a response to such observations, de-fluoridation treatments and technologies are drawing wide interest. More generally, there is a growing need for systems capable of recognition, binding and/or sensing of fluoride in a competitive and aqueous environment. In view of the pharmacological and environmental importance of fluoride, considerable effort has been devoted to the development of optical chemosensors for $\mathrm{F}^{-} \cdot{ }^{9-11}$ In the case of fluoride, the development of potent receptors which are operational in water is difficult because of the high solvation enthalpy of $\mathrm{F}^{-}\left(\Delta H_{1}=-504 \mathrm{~kJ} \mathrm{~mol}^{-1}\right){ }^{12}$ Consequently, few of the reported systems tolerate aqueous conditions ${ }^{10}$ or work in pure water. ${ }^{11}$ Successful examples of optical chemosensors for the detection of fluoride in water are based on strong Lewis acids (e.g., lanthanide, zirconium or organoboron compounds), or on silicon, which features particularly stable Si-F bonds. ${ }^{10,11}$ In some cases, detection of fluoride at concentrations close to or below the maximum 
contaminant level defined by the US Environmental Protection Agency $\left(4.0 \mathrm{mg} \mathrm{L}{ }^{-1}, 211 \mathrm{mM}\right)^{13}$ could be achieved. However, the preparation of these chemosensors often requires substantial synthetic effort (scheme 1).

An alternative sensing scheme involves the detection of an anion by sensing of a cation. An 'umpolung' of this kind can be achieved if the anion forms a very stable complex with the cation. Cyanide, for example, binds strongly to $\mathrm{Cu}^{2+}$ to yield $\left[\mathrm{Cu}(\mathrm{CN})_{\mathrm{x}}\right]^{n-}$ complexes. The concentration of cyanide can thus be related to the concentration of 'free' $\mathrm{Cu}^{2+}$, which can be detected by cation-specific sensors. In a similar fashion, fluoride is able to complex metal ions such as $\mathrm{Al}^{3+},{ }^{14} \mathrm{Th}^{4+15}$ and $\mathrm{Zr}^{4+},{ }^{16}$ and competitive reactions with metal-binding dyes can be used to quantify fluoride concentration. Among the various approaches to sense fluoride, sensors utilizing aluminium-fluoride affinity draw our special attention. Fluoride is known to react with aluminium ions to form very stable $\mathrm{AlF}_{3}$ species.

In our study on sensing of different analytes, ${ }^{17}$ we have reported a novel naphthalene-based benzene tripod receptor, ${ }^{17 a}$ which can selectively recognize aluminium and lead ions in the physiological conditions. However, this sensor displayed a large fluorescence enhancement effect upon the addition of aluminium and lead ions. In this study, we utilized the aluminium selective probe for the selective detection of fluoride. In order to demonstrate the practical utility of the new assay, we further applied it to sense fluoride in tap water and waste water, which provide more competitive media.

\section{Experimental}

\subsection{General information and materials}

All the materials used for synthesis were purchased from commercial suppliers and used without further purification. The sensor $\mathbf{L}_{\mathbf{1}}$ was synthesized according to the reported procedure. ${ }^{17 a}$ The spectroscopic studies were carried out in a mixed solvent of acetonitrile: aqueous HEPPES buffer (2:3). To check the sensing behaviour of the in situ formed Al-complex, $\mathbf{L}_{\mathbf{1}}$ and metal ions were mixed in 1:1 ratio within the cuvette at $\mathrm{pH} 7.4$ (1 mM pH 7.4 HEPPES). In the sensing process of fluoride in waste water, experiments were conducted in the same mixture solvent media. The buffer was replaced by tap water (TW), pond water (PW) and river water (RW); and in these mixtures $\mathbf{L}_{\mathbf{1}}$, $\mathrm{Al}^{3+}$ and $\mathrm{F}^{-}$were added, respectively.

\subsection{Determination of detection limit}

The detection limit was calculated using the following equation.

$$
\text { Detection limit }=3 \sigma / k \text {, }
$$

where $\sigma$ is the standard deviation of blank measurement, and $k$ is the slope between the ratio of emission intensity and concentration of analyte.

\section{Result and Discussion}

When 1 equivalent of aluminium ion was added to sensor $\mathbf{L}_{\mathbf{1}}$, large fluorescence enhancement was observed.

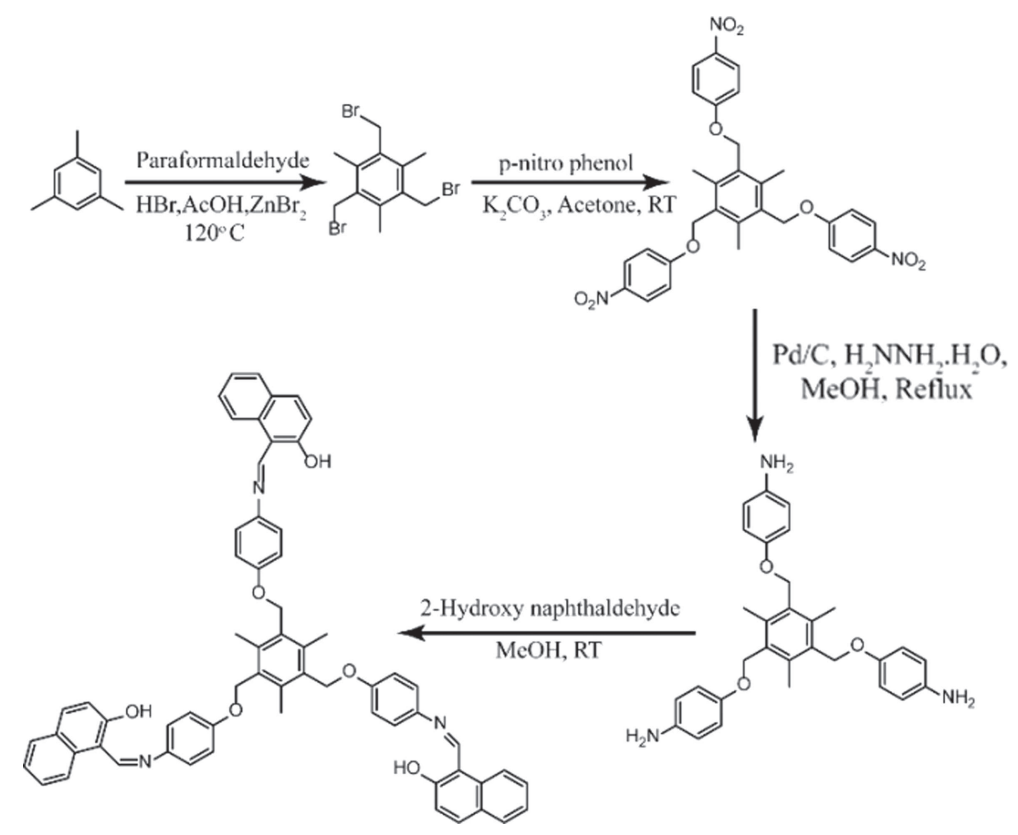

Scheme 1. Synthetic scheme of $\mathbf{L}_{\mathbf{1}}$. 


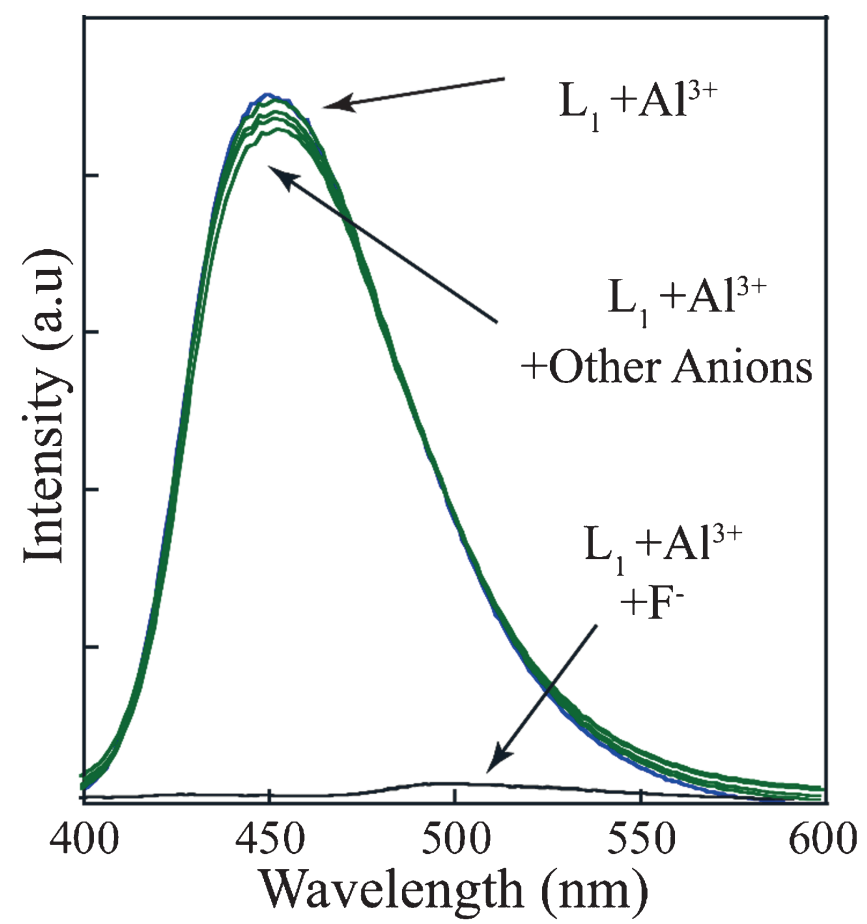

Figure 1. Changes in fluorescence emission spectra of $\mathbf{L}_{\mathbf{1}} \cdot \mathbf{A l}^{\mathbf{3}+}(10 \mu \mathrm{M})$ in the mixed solvent upon addition of different anions.

Among various anions such as $\mathrm{SCN}^{-}, \mathrm{AcO}^{-}, \mathrm{F}^{-}$, $\mathrm{Cl}^{-}, \mathrm{Br}^{-}, \mathrm{I}^{-}, \mathrm{H}_{2} \mathrm{PO}_{4}^{-}, \mathrm{HSO}_{4}^{-}, \mathrm{NO}_{3}^{-}$and $\mathrm{ClO}_{4}^{-}$, only $\mathrm{F}^{-}$showed a large fluorescence quenching (figure 1), resulting in 'On-Off' type sensing of fluoride. Fluorescence emission spectra of the receptor $\mathbf{L}_{\mathbf{1}} \cdot \mathbf{A l}^{3+}(25 \mu \mathrm{M})$ at RT in HEPES buffer $\left(\mathrm{CH}_{3} \mathrm{CN} / \mathrm{H}_{2} \mathrm{O}=2: 3\right.$, v/v, $\mathrm{pH}=$ 7.4) show a dramatic quenching $\left(\lambda_{\mathrm{ex}}=360 \mathrm{~nm}, \lambda_{\mathrm{em}}=\right.$ $450 \mathrm{~nm}$ ) on addition of fluoride anion. To learn more about the properties of the aluminium complex of $\mathbf{L}_{\mathbf{1}}$ as a receptor for fluoride, a titration of the receptor is performed with increasing concentration of fluoride. The fluorescence intensity of $\mathbf{L}_{\mathbf{1}} \cdot \mathbf{A l}^{\mathbf{3}+}$ complex decreased as the concentration of tetra-butyl ammonium fluoride salt increased and gets saturated after the addition of 3 equivalents of fluoride. The colour of the solution changed from blue to colourless under the UV lamp as shown in figure 2 (inset). As illustrated in figure 3 , the receptor system exhibited high sensitivity towards fluoride over other anions as the other anions show little or no interference in the sensing process of fluoride. From the titration, it was found that our system can detect fluoride in nanomolar range in the physiological condition.

The detection limit was calculated as $9.71 \mathrm{ppb}$. We have also checked the effect of the counter anions of $\mathrm{Al}^{3+}$ by using chloride, nitrate, perchlorate and sulphate salts of $\mathrm{Al}^{3+}$. It was seen that these counter anions did not affect the quenching process. Careful investigation

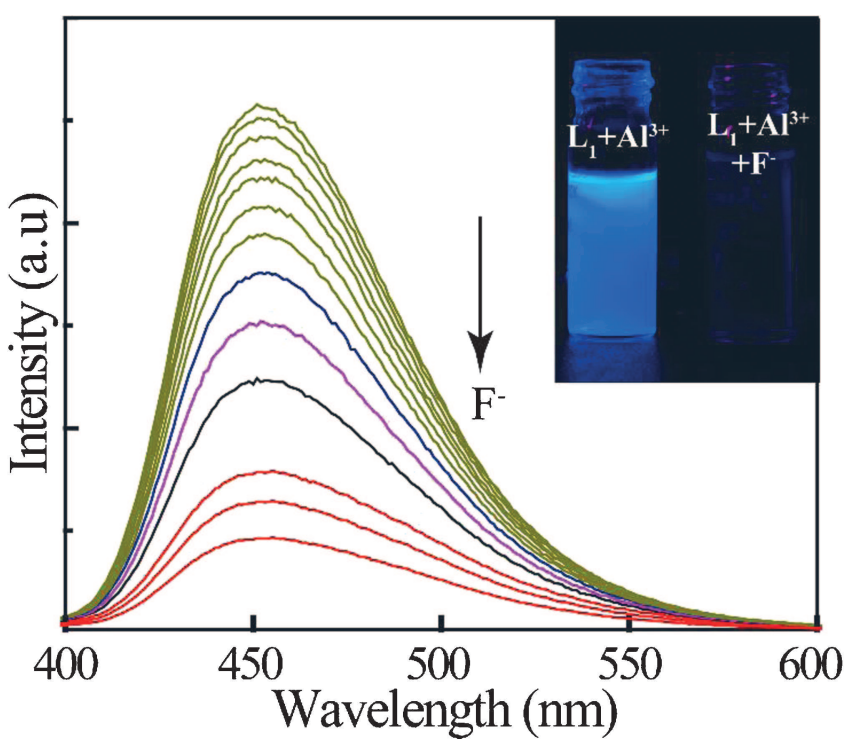

Figure 2. Changes in the fluorescence emission spectra of $\mathbf{L}_{\mathbf{1}} \cdot \mathbf{A l}^{\mathbf{3}+}(10 \mu \mathrm{M})$ in the mixed solvent upon addition of increasing concentration of $\mathrm{F}^{-}$. Inset: Visual change in fluorescence of $\mathbf{L}_{\mathbf{1}} \cdot \mathbf{A l}^{3+}$ in the presence of fluoride.

of the $\mathrm{pH}$-dependent response experiments of this probe to fluoride were also carried out in the $\mathrm{pH}$ range of 5.09.0. Results indicate that the system responds to fluoride within the $\mathrm{pH}$ range of 6.0-8.5.

Selectivity of the sensing assay towards fluoride was tested by performing the experiment in the presence of potentially interfering analytes. It was found that the system is unresponsive to most anions, in particular to heavier halides $\left(\mathrm{Cl}^{-}, \mathrm{Br}^{-}, \mathrm{I}^{-}\right)$, pseudohalides $\left(\mathrm{N}^{3-}, \mathrm{SCN}^{-}\right)$, and that bisanionic species $\left(\mathrm{CO}_{3}^{2-}\right.$ (converted to $\mathrm{HCO}_{3}^{-}$at $\left.\mathrm{pH} 7.0\right), \mathrm{SO}_{4}^{2-}$ ) give weak or negligible response, respectively. A comparison of the fluorescence responses obtained for these anions

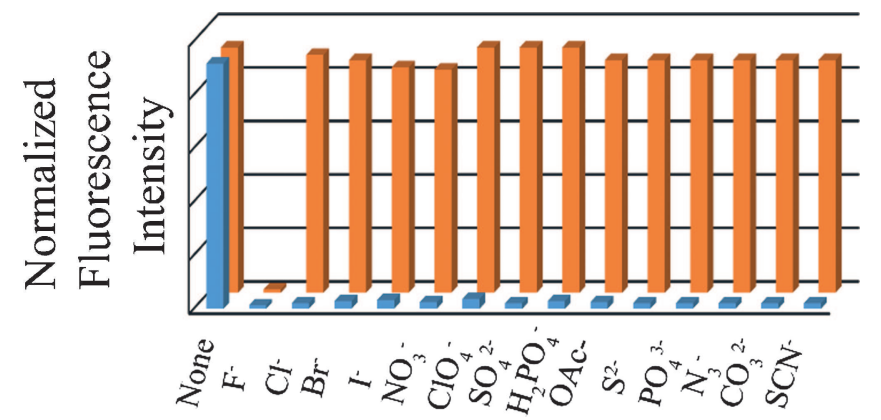

Figure 3. Normalized fluorescence responses of $\mathbf{L}_{\mathbf{1}} \cdot \mathbf{A} \mathbf{l}^{3+}$ to various anions in mixed solvent. Yellow bars represent emission intensities of $\mathbf{L}_{\mathbf{1}}$ in the presence of anions of interest (5 equivalents). Blue bars represent the change of the emission that occurs upon subsequent addition of fluoride to the above solution. Intensities were recorded at $450 \mathrm{~nm}$. 


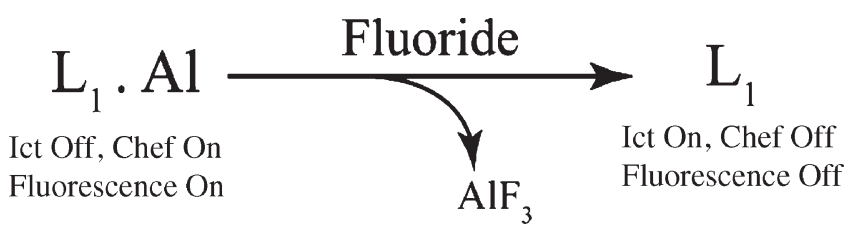

Scheme 2. Proposed sensing mechanism of fluoride by $\mathrm{L}_{\mathbf{1}} \cdot \mathbf{A \mathbf { l } ^ { 3 + }}$.

$(5.0 \mathrm{mM})$ and for fluoride $(1.0 \mathrm{mM})$ is shown in figure 3 .

As illustrated in scheme 2, the fluorescence signal transduction occurs via reversible chelation enhanced fluorescence (CHEF) processes with the metal ion. Enhancement of fluorescence is probably due to the formation of a six-member chelate ring with the metal ion, which enhances conjugation in the ligand framework and in turn results in fluorescence enhancement. In the absence of $\mathrm{Al}^{3+}$ ions, the extent of intramolecular charge transfer (ICT) in $\mathbf{L}_{\mathbf{1}}$ was sufficient enough to quench its fluorescence. Again, the rigidity of the system increases as the free rotation around the azomethine bond with respect to the naphthalene ring was restricted by bonding with $\mathrm{Al}^{3+} .{ }^{17 \mathrm{a}}$ In presence of fluoride, as aluminium has more affinity towards fluoride, the aluminium comes out from the $\mathbf{L}_{\mathbf{1}} \cdot \mathbf{A l}^{\mathbf{3}+}$ complex to form a more stable Al-F complex which causes the diminution of fluorescence intensity.

\subsection{Effect of $\mathrm{Pb}^{2+}$}

The effect of $\mathrm{Pb}^{2+}$ in the sensing of fluoride is important, as $\mathbf{L}_{\mathbf{1}}$ is a sensor for both $\mathrm{Al}^{3+}$ and $\mathrm{Pb}^{2+}$. So,

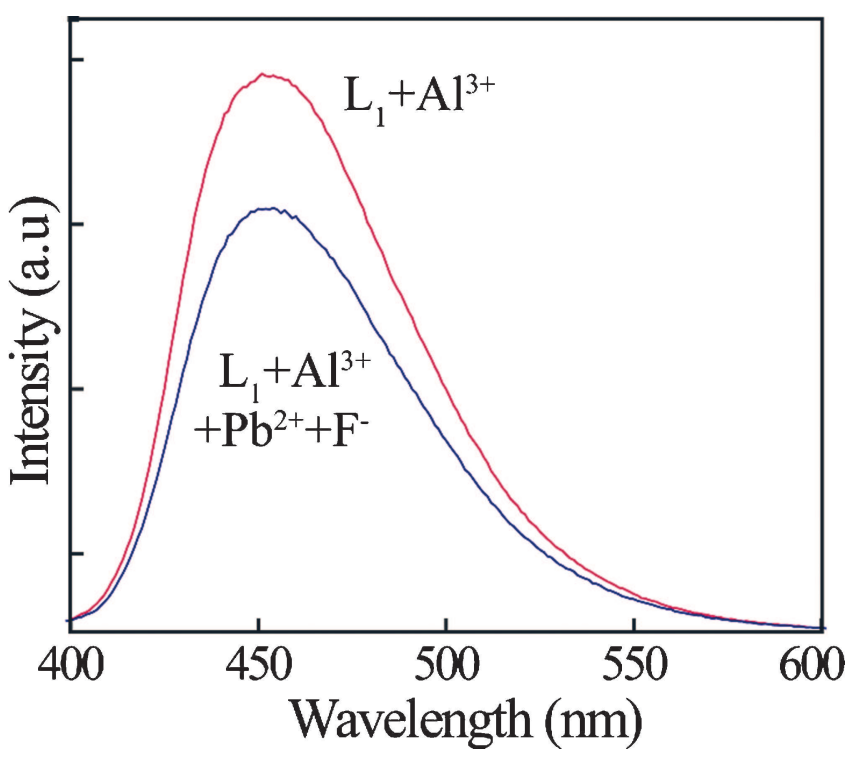

Figure 4. Effect of $\mathrm{Pb}^{2+}$ on the sensing behaviour of $\mathbf{L}_{\mathbf{1}} \cdot \mathbf{A l}^{\mathbf{3}+}$ towards fluoride.

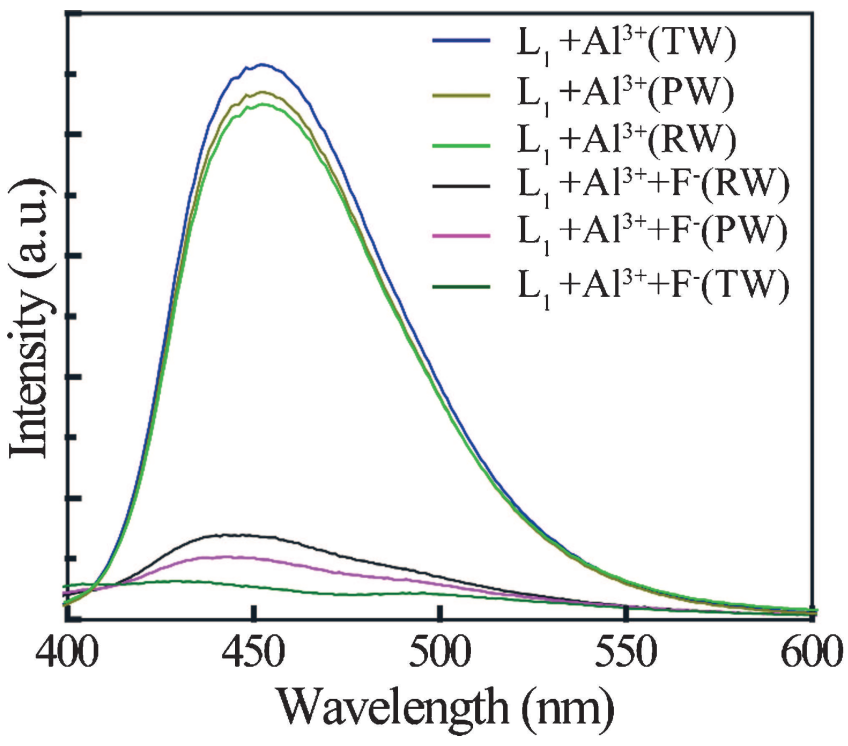

Figure 5. Sensing of fluoride by $\mathbf{L}_{\mathbf{1}} \cdot \mathbf{A l}^{\mathbf{3}+}$ in tap water (TW), pond water (PW) and river water (RW).

an experiment was carried out to check the effect of $\mathrm{Pb}^{2+}$ on the sensing of fluoride in media which was mentioned earlier. As the enhancement in fluorescence intensity of $\mathbf{L}_{\mathbf{1}}$ for $\mathrm{Al}^{3+}$ is greater than that of $\mathrm{Pb}^{2+}$, when fluoride was added in presence of $\mathrm{Pb}^{2+}$ in the mixture of $\mathbf{L}_{1} \cdot \mathbf{A l}^{3+}$ complex, the emission intensity was reduced but not completely quenched as shown in figure 4. This may be due to the fact that when fluoride snatches out $\mathrm{Al}^{3+}$ from the $\mathbf{L}_{\mathbf{1}} \cdot \mathbf{A l}^{3+}$ complex, $\mathrm{Pb}^{2+}$ captures the empty place caused by the release of $\mathrm{Al}^{3+}$ from the $\mathbf{L}_{\mathbf{1}} \cdot \mathbf{A l}^{\mathbf{3}+}$ complex and forms a complex with $\mathbf{L}_{\mathbf{1}}$ which prohibits complete quenching of emission intensity. So, it is obvious that $\mathrm{Pb}^{2+}$ interferes in the sensing process of fluoride by the receptor, $\mathbf{L}_{1} \cdot \mathbf{A l}^{3+}$.

In order to establish the practical utility of our sensing system, we have extended this to sense fluoride in tap water and river water. As shown in figure 5, our system was able to detect fluoride in tap water, pond water and river water, where the media were more complicated. Although, the media were more competitive than the media used for sensing fluoride, our system can detect fluoride without any interference. From our results it is evident that the new assay is useful for practical purposes.

\section{Conclusion}

We have developed a novel assay using an aluminium complex of naphthalene-based benzene tripodal for the detection of fluoride in physiological condition. The receptor $\mathbf{L}_{\mathbf{1}}$ recognizes $\mathrm{Al}^{3+}$ by enhancement of fluorescence intensity and addition of fluoride to this 
solution-induced 'On-Off' type fluorescence quenching. The new system can detect fluoride in the nanomolar range. This sensing system was further applied for the detection of fluoride in more complicated media such as tap water, pond water and river water. Thus, this new system can be used for practical purposes.

\section{Supplementary Information}

The supplementary information can be seen in www. ias.ac.in/chemsci.

\section{Acknowledgements}

GD thanks CSIR (01/2727/13/EMR-II) and Science \& Engineering Research Board (SR/S1/OC-62/2011) New Delhi, India for financial support and CIF of IITG for providing instrument facilities. BKD and CK thank IIT Guwahati for fellowship.

\section{References}

1. (a) Lee C H, Miyaji H, Yoon D W and Sessler J L 2008 Chem. Commun. 24; (b) Yoon J, Kim S K, Singh N J and Kim K S 2006 Chem. Soc. Rev. 35 355; (c) Gunnlaugsson T, Glynn M, Tocci G. M, Kruger P E and Pfeffer F M 2006 Coord. Chem. Rev. 250, 3094; (d) Gale P A 2006 Acc. Chem. Res. 39 465; (e) Beer P D and Gale P A 2001 Angew. Chem., Int. Ed. 40 486; (f) Martínez-Máñez R and Sancenón F 2003 Chem. Rev. 103 4419; (g) Kim S K, Lee D H, Hong J I and Yoon J 2009 Acc. Chem. Res. 42 23; (h) Lee H N, Xu Z, Kim S K, Swamy K M K, Kim Y, Kim S J and Yoon J 2007 J. Am. Chem. Soc. 1293828

2. (a) Ripa L W 1993 J. Publ. Health Dent. 53 17; (b) McDonagh M S, Whiting P F, Wilson P M, Sutton A J, Chestnutt I, Cooper J, Misso K, Bradley M, Treasure E and Kleijnen J 2000 Br. Med. J. 321855

3. (a) Jagtap S, Yenkie M K, Labhsetwar N and Rayalu S 2012 Chem. Rev. 112 2454; (b) Wu R, Qian S S, Hao F, Cheng H, Zhu D and Zhang J 2011 Environ. Sci. Technol. 456041

4. (a) Gazzano E, Bergandi L, Riganti C, Aldieri E, Doublier S, Costamagna C, Bosia A and Ghigo D 2010 Curr. Med. Chem. 17 2431; (b) Spittle B 2011 Fluoride 44 117; (c) Grandjean P and Landrigan P J 2006 Lancet 368 2167; (d) Olivier B L Arreola M and Luz M D R 2010 Chem.-Biol. Interact. 188319

5. (a) Zhang M, Wang A G, Xia T and He P 2008 Toxicol. Lett. 179 1; (b) Wurtz T, Houari S, N Mauro, MacDougall M, Peters H and Berdal A 2008 Toxicology 24926

6. Baker J L, Sudarsan N, Weinberg Z, Roth A, Stockbridge R B and Breaker R R 2012 Science 335233

7. Clark J H 1980 Chem. Rev. 80429
8. (a) Reddy M A and Fichtner M 2011 J. Mater. Chem. 21 17059; (b) Subbaiyan N K, Hill J P, Ariga K, Fukuzumi S and D'Souza F 2011 Chem. Commun. 47 6003; (c) Cook G J R, Parker C, Chua S, Johnson B, Aksnes A K and Lewington V J 2011 EJNMMI Res. 1 4; (d) Li Y, Schiepers C, Lake R, Dadparvar S and Berenji G R 2012 Bone 50 128; (e) Grochala W 2009 J. Mater. Chem. 19 6949; (f) Trewin A, Darling G R and Cooper A I 2008 New J. Chem. 3217

9. (a) An B K, Wang X, Burn P L and Meredith P 2010 Chem. Phys. Chem. 11 3517; (b) Qu Y, Hua J and Tian H 2010 Org. Lett. 12 3320; (c) Bhosale S V, Bhosale S V, Kalyankar M B and Langford S J 2009 Org. Lett. 11 5418; (d) Jung H S, Kim H J, Vicens J and Kim J S 2009 Tetrahedron Lett. 50 983; (e) Hudnall T W and Gabbaï F P 2008 Chem. Commun. 4596; (f) Dorsey C L, Jewula P, Hudnall T W, Hoefelmeyer J D, Taylor T J, Honesty N R, Chiu C W, Schulte M and Gabbaï F P 2008 Dalton Trans. 4442; (g) Jiang X, Vieweger M C, Bollinger J C, Dragnea B and Lee D 2007 Org. Lett. 9 3579; (h) Tan W, Zhang D, Wang Z, Liu C and Zhu D 2007 J. Mater. Chem. 17 1964; (i) Parab K, Venkatasubbaiah K and Jäkle F 2006 J. Am. Chem. Soc. 128 12879; (j) Lin Z, Ou S, Duan C, Zhang B and Bai Z 2006 Chem. Commun. 624; (k) Vázquez M, Fabbrizzi L, Taglietti A, Pedrido R M, González-Noya A M and Bermejo M R 2004 Angew. Chem. Int. Ed. 43 1962; (1) Kim T H and Swager T M 2003 Angew. Chem., Int. Ed. 42 4803; (m) Cho E J, Moon J W, Ko S W, Lee J Y, Kim S K, Yoon J and Nam K C 2003 J. Am. Chem. Soc. 125 12376; (n) Yamagushi S, Akiyama S and Tamao K 2001 J. Am. Chem. Soc. 123 11372; (o) Black C B, Andrioletti B, Try A C, Ruiperez C and Sessler J L 1999 J. Am. Chem. Soc. 12110438

10. (a) Guha S and Saha S $2010 \mathrm{~J}$. Am. Chem. Soc. 132 17674; (b) Wang F, Wu J, Zhuang X, Zhang W, Liu W, Wang P and Wu S 2010 Sens. Actuators B 146 260; (c) Yang X F, Qi H, Wang L, Su Z and Wang G 2009 Talanta 80 92; (d) Kim S Y and Hong J I 2007 Org. Lett. 9 3109; (e) Gao X, Zheng H, Shang G q and Xu J G 2007 Talanta 73 770; (f) Lee M H, Agou T, Kobayashi J, Kawashima T and Gabbaï F P 2007 Chem. Commun. 1133; (g) Zhu C Q, Chen J L, Zheng H, Wu Y Q and Xu J G 2005 Anal. Chim. Acta. 539 311; (h) Takahashi Y, Tanaka D A P, Matsunaga H and Suzuki T M 2002 J. Chem. Soc., Perkin Trans. 2 759; (i) Cooper C R, Spencer N and James T D 1998 Chem. Commun. 1365

11. (a) Andolina C M and Morrow J R 2011 Eur. J. Inorg. Chem. 154; (b) Hu R, Feng J, Hu D, Wang S, Li S, Li Y and Yang G 2010 Angew. Chem., Int. Ed. 49 4915; (c) Kim Y and Gabbaï F P 2009 J. Am. Chem. Soc. 131 3363; (d) Kim S Y, Park J, Koh M, Park S B and Hong J I 2009 Chem. Commun. 4735; (e) Matsunaga H, Kanno C, Yamada H, Takahashi Y and Suzuki T M 2006 Talanta 68 1000; (f) Yamamoto H, Ori A, Ueda K, Dusemund C and Shinkai S 1996 Chem. Commun. 407

12. Housecroft C E and Sharpe A G 2008 Inorganic chemistry, 3rd edn (Harlow: Pearson Education Ltd.) p. 537

13. Xu Z, Chen X, Kim H N and Yoon J 2010 Chem. Soc. Rev. 39127

14. Maity S B and Bharadwaj P K 2013 Inorg. Chem. 52 1161 
15. (a) Khalifa M E and Hafez M A H 1998 Talanta 47 547; (b) Hensley A L and Barney J E II 1960 Anal. Chem. 32 828; (c) Brownley F I Jr. and Howle C W Jr. 1960 Anal. Chem. 321330

16. (a) Zaporozhets O A and Tsyukalo L Y 2007 Anal. Chim. Acta 597 171; (b) Rohit, Kanwar L and Rao K K 2010 Sens. Actuators B 149 245; (b) Devine R F and Partington G L 1975 Environ. Sci. Technol. 9678

17. (a) Datta B K, Kar C, Basu A and Das G 2013 Tetrahedron Lett. 54 771; (b) Dey S K and Das G 2011 Chem. Commun.47 4983; (c) Pramanik A and Das G
2009 Tetrahedron. 65 2196; (d) Kar C, Basu A and Das G 2012 Tetrahedron Lett. 53 4754; (e) Basu A and Das G 2011 Dalton Trans. 40 2837; (f) Kar C, Adhikari M D, Ramesh A and Das G 2012 RSC Adv. 2 9201; (g) Kar C and Das G 2013 J. Photochem. Photobiol., A. 251 128; (h) Basu A and Das G 2012 Inorg. Chem. 51 882; (i) Kar C, Adhikari M D, Ramesh A and Das G 2013 Inorg. Chem. 52 743; (j) Datta B K, Mukherjee S, Kar C, Ramesh A and Das G 2013 Anal. Chem. 85 8369; (k) Kar C, Adhikari M D, Datta B K, Ramesh A and Das G 2013 Sens. Actuators B 1881132 